\title{
A study on Designing for Sustainable Product Development in view of End-User Role through Remanufacturing
}

\author{
S. Naik $^{1^{*}}$, R. Terkar ${ }^{2}$ \\ ${ }^{1}$ Assistant Professor, ${ }^{2}$ AssociateProfessor \\ ${ }^{1,2}$ SVKM's NMIMS Mukesh Patel School of Tech. Mgmt. \& Engg., Mumbai, India \\ \{naiksa1@gmail.com\}
}

\begin{abstract}
Sustainability requires diligent use of resources to avoid impairing the environment and addressing factors of scarcity. Recently the life of the products has decreased drastically which has made it necessary to plan for End-of-Life (EOL) options for the product. The design factors for the same need to be incorporated at an early stage of Prototyping for the New Product. Remanufacturing is now being accepted as a strategy for competitive advantage supported by government policies in western countries. Besides the Repairing, Reconditioning and Recycling; Remanufacturing has become the most advocated EOL options carried out by Original Equipment Manufacturer's (OEM's) OR $3{ }^{\text {rd }}$ Party Remanufacturers. Some OEM's attempt to integrate the same with Product Service System while others do not take it up for fear of cannibalization. For the success of Remanufacturing, optimization of newly added distinct process from the traditional manufacturing system is essential. It may be noted that the better the quality of core, the lesser will be the demand on Operations. The product should be so designed that the customer should be able to select the right EOL option at different life cycle phases of the product. Testing and Diagnosis techniques are central activities to the Remanufacturing Process. The dual role of the customer as an end user as well as a source of used product for Remanufacturing becomes important for setting up the measures for the Remanufacturing affiliated activities within the organization.
\end{abstract}

Keywords: Remanufacturing, OEM, $3^{\text {rd }}$ Party Remanufacturers, End-of-life Product Design

\section{Introduction}

All the various current issues such as the degradation of the environment, the diminution of energy resources, and waste disposal have stimulated a change from a mass manufacturing and mass consuming society toward a reutilizing society [1]. The Product Service Systems having focus on Innovation for fulfilling the requirements, traditionally aim at selling and servicing the physical products. However, such trends in manufacturing and consumption practices are not sustainable in long term [2]. Quality standards like ISO 14001 emphasize the need for sustainable product design which is encouraging the development of Models for the same [3]. Design strategies are now concentrating on Life cycle analysis with attention to low energy consumption [4]. Sustainability in all aspects has thus become critical to be looked at as the main goal rather than as a supplementary result. In the study on Axiomatic Design principles for Sustainable Product Development (SPD), it is emphasized that manufacturing sustainability can only be achieved if the product development takes into account the objectives of better EOL Management and making a green supply chain[5]. Green intervention strategies for SPD elaborate the need of sustainable marketing which encompasses the environmental concerns which focusses on use of recyclable packaging material and conveying the green attributes of the product [6]. SPD requires the user's participation in the process. The product is required to be monitored for its life cycle. Product requirements change over time. The development of technology and resource along with constraints must be deliberated. Remanufactured products inherently preserve the original value added in the first newly manufactured product thus reducing the requirement on scarce resources. The literature on process innovation indicates that the need of remanufacturing for sustainable development through product design innovation and environment friendly development is gaining prominence in industry [7, 8]. Remanufactured Product sometimes is a better version obtained by incorporating the upgraded changes [9].

B. Iyer, S. Nalbalwar and R. Pawade (Eds.)

ICCASP/ICMMD-2016. Advances in Intelligent Systems Research.

Vol. 137, Pp. 153-159.

(C) 2017. The authors - Published by Atlantis Press

This is an open access article under the CC BY-NC license (http://creativecommons.org/licens)es/by-nc/4.0/).

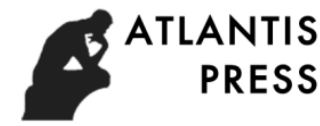


Remanufacturing is adopted more readily by $3^{\text {rd }}$ Party Remanufacturers than the OEM's themselves.To understand the reasons it is first important to have a closer look at the activities performed at the unit. Not all facilities working on used products can be classified as Remanufacturers. They may be a part of Product Recovery options at EOL (End-of- Life) stage. The difference between the four product recovery options -4 $\mathrm{R}$ 's i.e. Repair, Reconditioning, Remanufacturing and Recycling is often misunderstood.

\subsection{Product Recovery Processes - 4 R's}

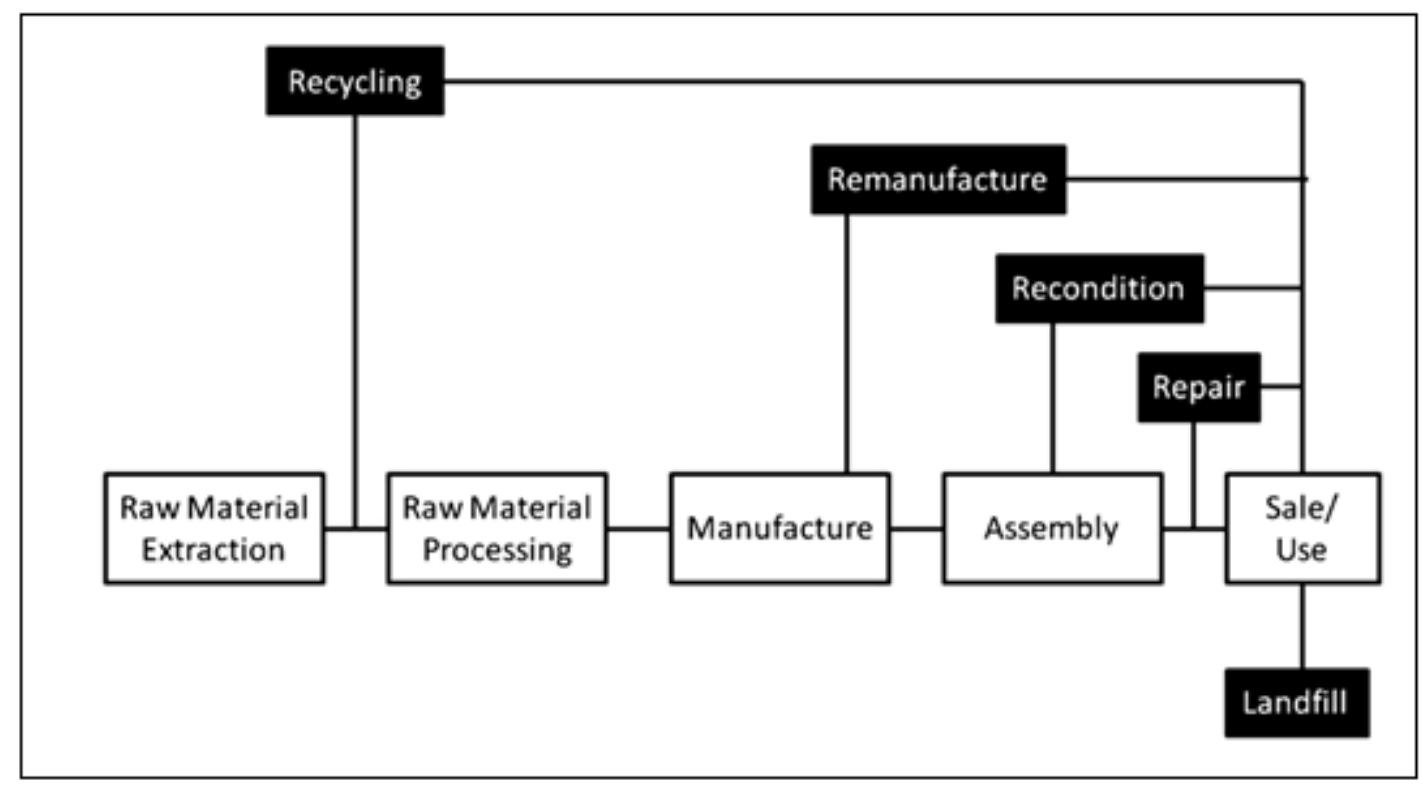

Fig.1. Levels of Product Recovery

It is imperative to understand and forecast the product returns to develop facilities for recovery [10]. Repair is the option in which the parts or sub-assemblies of the components that have been damaged are brought back to working condition. Recondition is the option in which the product is restored back to its original state including surface treatment to bring it back to the condition it was first received. However, no additional components are added. Remanufacturing is the process of bringing back an assembled product to "like-new" condition by restoring and rebuilding components back to their functional condition. Recycling is the process of breaking down the product to its Raw material so that it can be reused in the production process. A detailed discussion on comparison can be obtained between EOL Options is available in literature. Through the analysis of Bearing's product life cycle it has been illustrated how a product's life drastically decreases in absence of repairing and in spite of the high stress caused by fatigue, wear and corrosion; failure can be delayed by regular on time maintenance and concludes that higher productivity at lower cost can be obtained through the remanufacturing [11]. In one of the studies, after providing a robust definition of Remanufacturing, an analysis of Reuse of Municipal waste was carried out which concluded that Remanufacturing is the strongest approach of all [12].

\subsection{Remanufacturing Practices in different countries}

The application of Remanufacturing in Japan has been investigated in in four product areas viz., photocopiers, single-use cameras, auto parts, and ink and toner cartridges for printers where it is pointed out that developing appropriate core acquisition strategies and controlling the product quality to stimulate demand for remanufactured product is essential for successful Remanufacturing [13]. OEM's who engage in Remanufacturing build consumer demand by incorporating Remanufactured Components into the remanufactured product. Through his PESTEL analysis done in China, it is shown that Remanufacturing sector is treated as a prioritized sector and effect of government policies on the sector is analysed [14]. Remanufacturing is used as a Productivity tool for U.S. industries to gain more opportunities for a competitive advantage [15]. In all the cases, the strategy is in its developed stage and effectively used with the goals setting up for better productivity /profitability rather than just feasibility as is the case in India. It is claimed that the remanufacturing is developed in the western world while in India it is not treated as a separate sector but a supplementary activity taken up by the companies [16]. Government policies play a significant role in driving the interests of the Remanufacturers as a well as the customers. 


\section{Designing for Multi-Life Cycle Product}

When a product is designed for Multiple life-cycles it has to be planned for requirements not only for fitness for use of end-user but also for the End-of-Life of the product. The end-users generally give the requirement as per their current need. A literature review on various aspects of Remanufacturing was done indicating that it was firstly taken up for Sustainability and rising concerns over the depleting resources of the Environment. The stakeholders in the Remanufacturing process are the OEMs, 3rd Party Remanufacturers \& End users themselves. Government policies also play a vital role in the success of the Remanufacturing. From a study on literature for various techniques used for addressing Remanufacturing challenges, it may be concluded that following Design strategies exist : i) Design for Remanufacturability, ii) Design for Core Acquisition, iii) Design for Simplification and iv) Design for Eco-efficiency. Designing product with reference to suitability of Operations like Disassembly, Reassembly and Cleaning is vital. However, it is observed that little effort has been put into understanding the dynamic nature of customer requirements in the Remanufacturing process design [17-28].

\subsection{Remanufacturing by OEM and $3^{\text {rd }}$ Party Remanufacturers}

Remanufacturing may be taken up by OEM's or $3^{\text {rd }}$ Party Manufacturers' (3PRs). However, there is a difference. In case of OEM the objectives are for long-term financial benefits and sometimes environment sensitiveness too. However, in case of 3PR's it's because the OEM's shun from taking up the activity and they have a ready benchmark to follow with reduced need for market research. The concerns of OEM's and 3PR's taking up the remanufacturing activities is the latest challenge being explored. The issues have been compared in detail with reference to closed loop supply chain environment [29]. Remanufacturing facilities need not be a part of the firm. The activities can be outsourced too. It is claimed that Outsourcing is beneficial to OEM irrespective of whether the Remanufactured product demand is high or low [30]. The most important aspect for the organizations not entering into the field of remanufacturing is the fear of cannibalization [31]. The cannibalization may also affect the product returns as per the Product Life Cycle stage. The effect of cannibalization on product returns at growth and maturity stage of product life cycle is essential [32, 33]. Fear of cannibalization is one of the chief barriers to the success of Remanufacturing by OEM's in India although a recent change is being observed. For perfect launching of the Remanufactured product the Time to market should be reduced so as to get increased sales, product loyalty and longer sales life[34].

\subsection{End-user Role Transition}

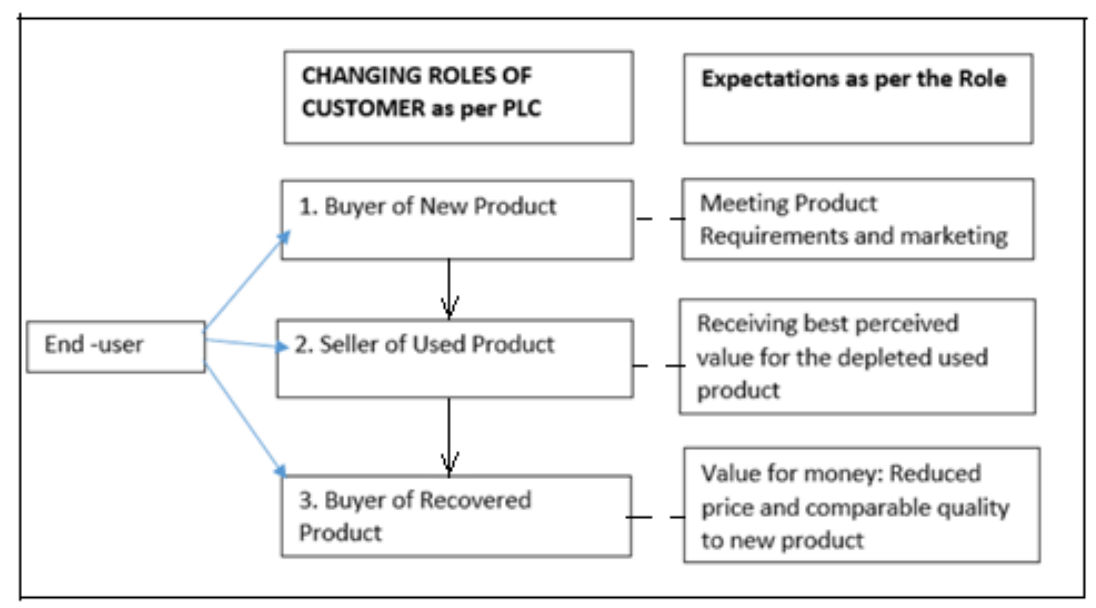

Fig. 2. Transitional Expectations as per End-user Role

As illustrated in Figure 2 for the success of Product Recovery resulting in Sustainable Product Development it is essential that the customer switches his role: a) Buyer of New Product; b) Seller of Used Product \& c) Buyer of Recovered Product as per the Product Life Cycle. The first role is accepted by the customer when he chooses to buy the product to meet his needs among different options. If he is fully satisfied and delighted with the product then the customer's requirements can be said to have been met and the sold product can be taken as the 
benchmark for producing Remanufactured product assuming the product requirements don't change much over time lag between the time to market of new product and that of the Remanufactured product. The third role is accepted by the customer if he gets better price differential for same or sometimes better quality from the Remanufactured Product as comparable to the new product. Awareness for positive contribution to the environment and society as well as government policies may motivate the customer to switch roles [35].

However, the second role as the seller of the used product is one of the most complicated ones as customer is not accustomed to be a seller and mostly throw away the product after first use. Here, the Product Return Acquisition strategy is crucial as without the cores remanufacturing is not possible. The customer may be unable to judge whether the product has really reached its End-of-Life. This EOL stage changes as per perception from customer to customer. Thus the Core Acquisition Process not only involves reverse logistics but also designing the product for End-of- Life stage to motivate the customer. Generally, the OEM's and 3PR's compete with each other in the second and third role of the customer. Although the OEM's are at an advantage in the first role of the customer, the 3PR's may still compete with their new products by offering an aesthetically upgraded product, better than the new. The role of visualization at prototyping stage is applicable in the NPD phase of Customized Remanufacturing [36]. This is employed in Remanufacturing of vehicles which are priced equal or higher than the parallel New product available in the market. Customer for Automobile sector looks forward to a vehicle which looks equal or better than the new. Applying the creative visualization principles for few minor modifications in form, structure, dimension, material and surface, the value of the revamped Remanufactured product improves drastically. OEM's need to ensure that they have the best design and get the IPR's for the same. Thus OEM's and 3PRs are in competition with each other in all the roles of the customer. OEM's however make heavy investment for the first role of customer in determining the customer requirements and designing of product as well as process for feasible manufacturing of the product. To recover the cost it is imperative that OEM's ensure maximum profit using brand image they develop for the customer and competing in the Remanufacturing of its own product. Planning should start right from the material selection at the early design stage to make the product recyclable and remanufacturable. Material value is the least value that may be recovered. It is imperative that the core acquired conserves most of the value added [37].

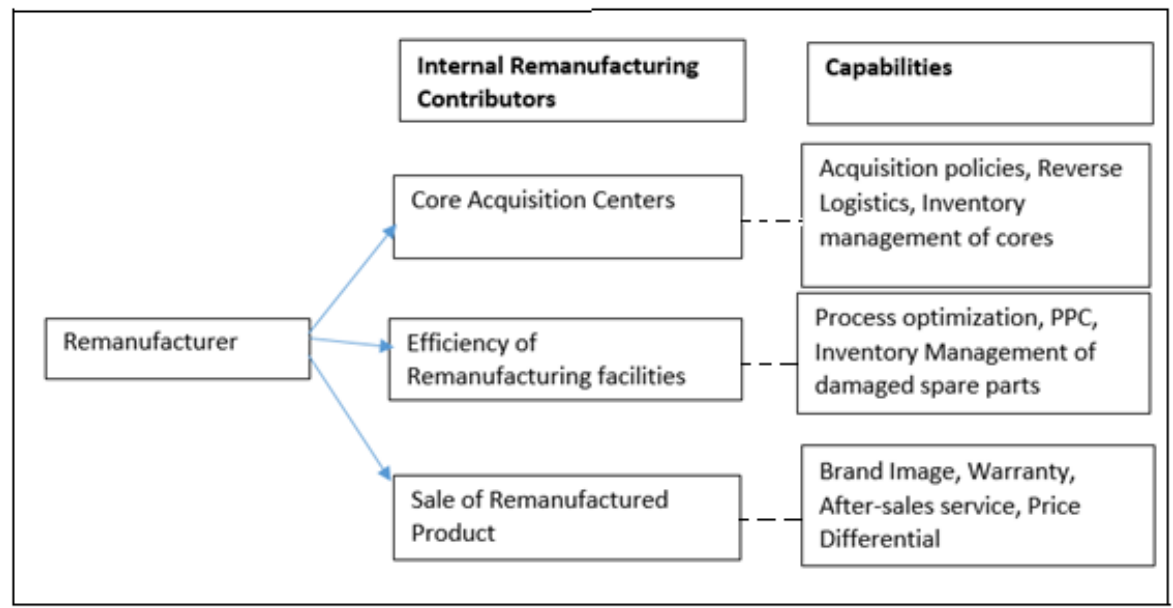

Fig. 3. Remanufacturing sections and their capabilities

The various capabilities on which the efficiency of each of the Internal Remanufacturing Sections is measured for meeting the customer requirements is illustrated in Figure 3. While the customer transcends in the three roles, Remanufacturer has three major contributing sections who need to optimize the feasibility and success of Remanufacturing: i) Product collection centres, ii) Remanufacturing facilities and iii) Remanufactured Product sales distribution. The capabilities may be increased through appropriate optimization. 


\section{Design Approach as applied for SPD}

In view of the above discussed design requirements an existing approach is hereby illustrated. There are certain processes where there has been a confusion in classification of the product as a Repaired, Reconditioned, Remanufactured or Recycled product. Re-treading of car tyres is an example of Remanufacturing process. However, the process may appear and sometimes be even rightly classified as a Repairing or Reconditioning activity. The key is to make it "as good as new". Poor quality of such work discourage the customer and unfortunately a not-so-good imprint of the Remanufacturing activity in general. For this process different procedures are followed by different organisations. As per one of the organisations which was one of the first to be certifying its unit for this Remanufacturing of tyre process with ISO Certification - ISO 9002 (Model for Quality Assurance in Production, Installation and Servicing) the process involves Receiving used tyres, Cleaning, Drying, Visual Analysis of imperfections, Buffing, Skiving, filing, gluing, tread application, curing and finally testing the remanufactured product rigorously. Currently such remanufactured tyres are used for critical applications like aircrafts and vehicles for emergency civic services.

In the Indian context, we observe that there are innumerable heavy vehicles moving around transporting the necessary commodities. The wearing of tyres is unavoidable. Interviews of customers from major transportation companies was conducted to gain insight into their expectations. It was found that the cores (used tyres) are more readily submitted back by the customers as they have the system of carrying an extra tyre, thus creating a space for this luggage to be traded later. From the Remanufacturer's perspective, better reverse logistics is thus not always the key for better core acquisition, except for a strategic accessible location. Although there are garages, they are not trusted as mediators. Customers prefer direct interaction with the Remanufacturer. If unreachable, the authorized dealers provide a credit note as per the condition of the tyre. The customers who submit the cores, create the demand for the Remanufactured product themselves. They do expect a remanufactured - "as good as new" tyre in return with minimum differential price. However, they don't have brand affiliation and thus can accept a $3^{\text {rd }}$ party product. In this case, after sales service for the Remanufactured product is of critical importance. Some Remanufacturer's prefer giving higher validity to lure the customers. The warranty is expected to be same for all vehicles of the same make. Knowing the usage pattern of the customer, some times higher warranty is also offered at a nominal price. The tendency of product abuse is high in this industry and so are misrepresentations. It is thus advisable to the Remanufacturers that they may extend the offers for better core acquisition and demand fulfilment provided they are able to stick to their warranty claims which are sometimes more than that offered with the new product itself. Also it may be observed that as a safety measure most of the remanufacturing organizations whether OEM or $3^{\text {rd }}$ party remanufacturer have the claim settlement clause of providing the compensation for maximum value equal to that of the product which may be mandatory for avoiding legal hassles. As seen here, an integrated approach to core acquisition and sales of Remanufactured product is attempted. Warranty, after-sales service and a transparent EOL evaluation is the key to Remanufacturing success.

\section{Conclusions}

A considerable amount of research on Production Planning \& Control (PPC) activities for Remanufacturing Facilities has been done. However, there is a lack of research for Core Acquisition as it is considered a peripheral activity. Unlike other raw materials and consumables, Core is the input to the Remanufacturing Process produced by the OEM's themselves with the selling rights transferred to the customers. The internal requirements for successful remanufacturing depends on generation of demand for remanufactured product, having flexible facilities and a good core acquisition strategy. In the case study of Remanufacturing of tyres, it was seen that after sales service and warranty claims help local remanufacturers acquire more cores, although they don't have a better reverse logistics resources. As per the claims of the industry tonnes of gallons of crude oil is saved via the process. Thus, designing process in view of sustenance of product for more than one life cycle will benefit and open up new opportunities for eco-efficient designs.

\section{References}

[1]. Takahashi, Katsuhiko, et al. "An adaptive pull strategy for remanufacturing systems." Journal of Intelligent Manufacturing 25.4 (2014): 629-645. 
[2]. E. Manzini, C. Vezzoli, "A strategic design approach to develop sustainable product service systems: examples taken from the 'environmentally friendly innovation' Italian prize", Journal of Cleaner Production, 11.8 (2003): 851-857

[3]. Lennart Y. Ljungberg, "Materials selection and design for development of sustainable products", Materials \& Design, 28. 2(2007): 466-479.

[4]. Alting, Leo. "Life cycle engineering and design." CIRP Annals-Manufacturing Technology 44, no. 2 (1995): 569-580.

[5]. Lee, Guang Beng, and Badrul Omar. "Sustainable Product Development Based On Axiomatic Design Principles: An Industrial Application." (2006).

[6]. Kinoti, Mary Wanjiru. "Green marketing intervention strategies and sustainable development: A conceptual paper." International Journal of Business and Social Science 2.23 (2011).

[7]. L.Sundaravel, J.Bharadwaj, M.Suresh Krishna, M. Vetheeswar (2015), Remanufacturing by Design Modification of Rocker Arm, International Journal of Innovative Research in Science, Engineering and Technology, 113.1 (2015): 56-64.

[8]. Sabanc, Huriye. "A review of the literature on process innovation in remanufacturing." International Review of Management and Marketing 2.3 (2012): 139.

[9]. G.D.Sivakumar, S.Godwin barnabas, S.Anatharam, "Indian Automobile Recycling Management", International Journal of Innovative Research in Science, Engineering and Technology, Vol 3, no.3, (2014), pp. 2754-2758

[10]. Zhou, Li, et al. "Forecasting return of used products for remanufacturing using Graphical Evaluation and Review Technique (GERT)." International Journal of Production Economics (2016).

[11]. Terkar, Ravi, Dr Hari Vasudevan, and Dr Vilas Kalamkar. "Enhancing Productivity through Cost and Lead Time Reduction in Remanufacturing." International Journal of Mechanical Engineering \& Technology (IJMET) 4.2 (2013): 286-297.

[12]. A.M. King, S.C. Burges, "Reducing waste: repair, recondition, remanufacture or recycle?" Sustainable Development, 14(2005), 257-267

[13]. Matsumoto, Mitsutaka, and Yasushi Umeda. "An analysis of remanufacturing practices in Japan." Journal of Remanufacturing 1.1 (2011): 1.

[14]. Wang, Yacan, et al. "Drivers And Obstacles Of The Remanufacturing Industry In China: An Empirical Study." International Journal of Industrial Engineering 22.1 (2015)

[15]. Giutini, Ron, and Kevin Gaudette. "Remanufacturing: The next great opportunity for boosting US productivity." Business Horizons 46.6 (2003): 41-48.

[16]. Israr, Mohammad, Anshul Gangele, and Kavita Kripalani. "Analysis and Optimization of Remanufacturing in India through Approaches, Potentials \& Technical challenges."

[17]. Yuksel, H., "Design of automobile engines for remanufacture with Quality function Deployment", International Journal of Sustainable Engineering, 3 (2010) :170-180

[18]. Z. Ghazallia \& A. Murata, "Development of an AHP-CBR evaluation system for remanufacturing: end-of-life selection strategy", International Journal of Sustainable Engineering, 4.1(2011):2-15.

[19]. Zwolinski, Peggy, Miguel-Angel Lopez-Ontiveros, and Daniel Brissaud. "Integrated design of remanufacturable products based on product profiles." Journal of Cleaner Production 14.15 (2006): 1333-1345.

[20]. Wei, Shuoguo, Ou Tang, and Weihua Liu. "Refund policies for cores with quality variation in OEM remanufacturing." International Journal of Production Economics 170 (2015): 629-640.

[21]. Matsumoto, Mitsutaka, et al. "Trends and research challenges in remanufacturing." International Journal of Precision Engineering and Manufacturing-Green Technology 3.1 (2016): 129-142.

[22]. Shi, Wenbo, and K. Jo Min. "Product remanufacturing and replacement decisions under operations and maintenance cost uncertainties." The Engineering Economist 59.2 (2014): 154-174.

[23]. Sakao, Tomohiko, and Hajime Mizuyama. "Understanding of a product/service system design: a holistic approach to support design for remanufacturing." Journal of Remanufacturing 4.1 (2014): 124.

[24]. Deng, Qianwang, Xiahui Liu, and Haolan Liao. "Identifying Critical Factors in the Eco-Efficiency of Remanufacturing Based on the Fuzzy DEMATEL Method." Sustainability 7.11 (2015): 15527-15547. 
[25]. Piñeyro, Pedro, and Omar Viera. "Analysis of the quantities of the remanufacturing plan of perfect cost." Journal of Remanufacturing 2.1 (2012): 1-8.

[26]. Li, Ming-Zheng, et al. "Feasibility study of a new approach to removal of paint coatings in remanufacturing." Journal of Materials Processing Technology 234 (2016): 102-112.

[27]. Lambert, Alfred JD. "Optimizing disassembly processes subjected to sequence-dependent cost." Computers \& Operations Research 34.2 (2007): 536-551.

[28]. Peters, Kristian. "Methodological issues in life cycle assessment for remanufactured products: a critical review of existing studies and an illustrative case study." Journal of Cleaner Production 126 (2016): 21-37.

[29]. Xiong, Yu, Quanwu Zhao, and Yu Zhou. "Manufacturer-remanufacturing vs supplierremanufacturing in a closed-loop supply chain." International Journal of Production Economics 176 (2016): 21-28.

[30]. Zou, Zong-Bao, et al. "Third-party remanufacturing mode selection: Outsourcing or authorization?." Transportation Research Part E: Logistics and Transportation Review 87 (2016): 1-19.

[31]. Vasudevan, Hari, Vilas Kalamkar, and Ravi Terkar. "Remanufacturing for Sustainable Development: KeyChallenges, Elements, and Benefits." International Journal of Innovation, Management and Technology 3.1 (2012): 84.

[32]. Kushwaha, Siddhartha, and Sourabh Bhattacharya. "The Impact of Cannibalization on Product Returns for Remanufacturing Under Different Demand Scenarios." IUP Journal of Operations Management 14.1 (2015): 39.

[33]. Vasudevan, H., V. Kalamkar, V. Sunnapwar, and R. Terkar. "Exploring the Potential of Remanufacturing in Indian Industries for Sustainability and Economic Growth." International Journal of Business Management \& Research (IJBMR), ISSN (P) (2014): 2249-6920.

[34]. Terkar, Ravi, et al. "Perfect Product Launching Strategies in the Context of Survival of Small Scale Consumer Products Industries." Technology Systems and Management. Springer Berlin Heidelberg, 2011. 321-326.

[35]. Yang, Wei, Yongzhi Zeng, and Yue Wu. "Research on factors that affect the eco-efficiency of remanufacturing closed-loop supply chain." Contemporary Logistics 2 (2011): 75.

[36]. Naik, Sawankumar, and Ravi Terkar. "Role and Significance of Visualisation in Product Design at Prototyping Stage." CAD/CAM, Robotics and Factories of the Future. Springer India, 2016. 625-636.

[37]. Yang, S. S., S. K. Ong, and A. Y. C. Nee. "A Decision Support Tool for Product Design for Remanufacturing." Procedia CIRP 40 (2016): 144-149. 